\title{
Assessment of fruit and vegetable consumption among female university students
}

\author{
${ }^{1}$ Ahmad Sirfan, A.S., ${ }^{1}$ Hamirudin, A.H. and ${ }^{2}$ Sidek, S. \\ ${ }^{1}$ Department of Nutrition Sciences, Kulliyyah of Allied Health Sciences, International Islamic University \\ Malaysia, Jalan Sultan Ahmad Shah, 25200 Kuantan, Pahang, Malaysia \\ ${ }^{2}$ Department of Psychology, Kulliyyah of Islamic Revealed Knowledge and Human Sciences, International \\ Islamic University Malaysia, Jalan Gombak, 53100 Kuala Lumpur, Malaysia
}

\begin{abstract}
Article history:
Received: 13 February 2020

Received in revised form: 13

April 2020

Accepted: 14 April 2020

Available Online: 2 May

2020
\end{abstract}

Keywords:

Fruits,

Vegetables,

Female,

University students,

Barrier

DOI:

https://doi.org/10.26656/fr.2017.4(5).067

\begin{abstract}
The low intake of fruits and vegetables is a global issue. This research aimed to determine the association of fruit and vegetable intake with waist circumference and barriers of intake. A total of 279 female students from the International Islamic University Malaysia, Kuantan, were recruited through convenience sampling and provided with a set of questionnaires to identify their fruits and vegetable intake. The waist circumference of respondents was measured. The majority of students consumed only one serving of fruit and vegetable per day, which is less than the levels recommended by the Malaysian Dietary Guideline. Only $9.0 \%$ of students had a fruits intake of two servings/day, while $6.5 \%$ had a vegetable intake of three servings/day which meets the recommendation. There was no significant association of fruits and vegetable intake with waist circumference among female students. Non-availability and not delicious were identified as major barriers to fruit and vegetable consumption respectively. In conclusion, the fruit and vegetable intake among the majority of female university students is inadequate. Thus, there is a need to increase awareness and develop strategies to promote adequate fruit and vegetable intake among this specific target group.
\end{abstract}

\section{Introduction}

A significant concern in diet and nutrition is the insufficient consumption of fruit and vegetable (FV). Globally, the pattern of fruits intake has gradually increased over the past two decades, but vegetable intake varies, with the majority of countries demonstrating less than optimal intake (Micha et al., 2015). According to Hall et al. (2009), 77.6\% of men and $78.4 \%$ of women from low- and middle-income countries have lower FV intake than the minimum recommended intake of five daily servings of FV. In Washington, only $5 \%$ to $6 \%$ of adults meet the Dietary Guidelines for Americans on Recommended Intakes of Fruit and Vegetable (Ta et al., 2012). Recent data from the World Health Organisation (WHO) (2019) estimated that about 3.9 million global deaths in 2017 were associated with inadequate consumption of FV.

FV are known for their richness in vitamins, minerals, electrolytes, phytochemicals, antioxidants and dietary fibre as well as in disease prevention and treatment (Slavin and Lloyd, 2012). Interestingly, FV intake has a significant impact on mental health as individuals meeting the recommended FV intake have a lower likelihood of moderate or high distress levels compared to those who did not (Richard et al., 2015; Bishwajit et al., 2017). Adequate intake of FV is very prominent in maintaining a balanced diet, health and well-being.

WHO (2003) recommends at least $400 \mathrm{~g}$ of FV daily, excluding starchy tubers, which is equal to five servings per day. This recommendation is parallel with the Malaysian Dietary Guidelines published in 2010 (National Coordinating Committee on Food and Nutrition, 2010). It states that the fifth key message is to consume at least five servings of fruits and non-starchy vegetables every day. The five servings refer to three servings of vegetables and two servings of fruits. In December 2016, the Department of Health of Ireland released a new and updated food pyramid. The FV section was changed from the second to the first shelf, which is the base of the pyramid with a recommended five to seven servings per day (Government of Ireland, 
2016).

Studies have been conducted to identify the adequacy of FV consumption. Pem and Jeewon (2015) noted that in 2012, the mean intakes for fruit and vegetable in Malaysia are $179 \mathrm{~g} /$ day and $133 \mathrm{~g} /$ day, respectively, which are still below the recommendation. Among Sri Lankan university students, Perera and Madhujith (2012) found that the FV consumption is below the recommendations. Other studies also reported the inadequacy of FV intake, which is below the recommended intake (Herbert et al., 2010; Gan et al., 2011; Teschl et al., 2018).

Sufficient FV consumption also provides multiple beneficial consequences on some metabolic diseases. For instance, body adiposity and abdominal obesity are inversely correlated with higher intake of FV ( $\mathrm{Yu}$ et al., 2018). According to WHO (2008), waist circumference is an indicator of abdominal obesity. It has been shown that abdominal obesity can aggravate the risk of cardiovascular disease (CVD), insulin resistance, and dyslipidaemia (Zhang et al., 2008). Studies have emphasised that FV intake is associated with reduced risk of cardiovascular disease, cancer and all-cause mortality (Hartley et al., 2013; Wang et al., 2014; Aune et al., 2017). Mo and colleagues (2019) demonstrated that a moderate increase in FV intakes such as an additional of half serving of fruit or one serving of vegetable would gradually minimise the percentage of CVD from $12.6 \%$ to $8.5 \%$. Yip et al. (2019) stated that there is a $10 \%$ to $30 \%$ reduction in the risks for associated diseases. Furthermore, there is a significant association between green leafy vegetable consumption and incidence of diabetes, suggesting a beneficial effect of green leafy vegetables in reducing the risk of diabetes (Cooper et al., 2012; Li et al., 2014). Li et al. (2014) highlighted that the intake of fruit is also associated with a remarkably reduced risk of type 2 diabetes. It is notable that FV provides abundant health benefits. Additionally, a higher intake of vegetable or fruit results in weight loss (Ghalaeh et al., 2012; Mytton et al., 2014).

Several barriers related to inadequate consumption of FV have been reported. According to Perera and Madhujith (2012), the highest barriers of FV intake are non-availability and prices, with almost $83.4 \%$ of students stating that their place of residence influences their FV intake. Other study identified a barrier in which young adults moving away from home to live in halls tend to have limited choices of FV (Herbet et al., 2010). Another finding consistently showed that FV intake is lower among students after entering college as they tend to eat FV based on their preference (Hakim et al., 2012). Meanwhile, environmental factors also play a big role in influencing FV intake, especially availability (Othman et al., 2012).

With the heightened concern on the importance of sufficient FV intake, this study was conducted among female university students due to the scarcity of comprehensive research related to this topic, particularly in Malaysia. Furthermore, females were selected as study participants due to significantly higher rates of abdominal obesity among female as reported in the National Health and Morbidity Survey 2015 (Institute for Public Health, 2015); and lower intake of fruits and vegetable in this age group based on the findings by the Malaysian Adults Nutrition Survey (MANS) 2014 (Institute for Public Health, 2014). Hence, this study aimed to determine the fruit and vegetable intake among female university students, the association of fruit and vegetable intake with waist circumference, and barriers of fruit and vegetable intake. The findings will be beneficial for future planning to promote adequacy of $\mathrm{FV}$ intake as well as healthy eating and lifestyles.

\section{Materials and methods}

\subsection{Study design and respondents}

A cross-sectional study was conducted among female students of the International Islamic University Malaysia (IIUM) Kuantan Campus from four eligible kulliyyahs (faculties). The criteria for inclusion and exclusion were set prior to data collection. The inclusion criteria of this study were healthy undergraduate Malaysian female students of IIUM Kuantan (first to fourth year students) and age ranging from 19 to 26 years old. The exclusion criteria were students diagnosed with diseases or disorders which might impair their FV intake such as gastrointestinal disorders. Additionally, the students in the fifth year of study were excluded in order to standardise the participants from different kulliyyahs with four years of study duration.

\subsection{Data collection}

Data were obtained through convenience sampling. Information regarding the study was explained to the respondents, and informed consent forms were completed by potential respondents prior to their participation.

\subsubsection{Measures}

A set of self-administered questionnaires was distributed to the respondents who were required to answer all questions provided. Pre-testing was conducted among $10 \%$ of the total sample size to test the questionnaires prior to data collection. 


\subsubsection{Sociodemographic}

Sociodemographic data of the participants were collected. The data consists of name, matric number, phone number, age, year of study and kulliyyah.

\subsubsection{Waist circumference}

The waist circumference of the respondents was measured using a flexible measuring tape between the highest part of the iliac crest and lowest palpable rib based on established guideline published by WHO (2008). The tape was snugged around the respondents' body but not too tight. Measurement values were taken when respondents exhaled. The measurements were performed by a researcher to avoid bias and measurement error. The cut-off values of waist circumference were referred to the South Asian guidelines by WHO (2008), which stated that the ideal waist circumference for female South Asian is less than $80 \mathrm{~cm}$

\subsubsection{Fruit and vegetable intake}

The second section comprises questions on frequency, types, number of serving, and eating time of FV intake. The structured questions on frequency and number of servings were adopted from a study by AlOtaibi (2014) which was conducted among students in different countries. A comparison of respondents' FV intake according to serving size in this present study was made against the Malaysian Dietary Guidelines (National Coordinating Committee on Food and Nutrition, 2010). Recommended serving size for daily fruit intake is two servings, while the daily recommendation for vegetable intake is three servings (Tee, 2011).

\subsubsection{Barriers of FV consumption}

The last section concerns the barriers of FV consumption. The questions on the barriers of consumption were adopted from Perera and Madhujith (2012) and Al-Otaibi (2014).

\subsection{Statistical analysis}

The data were analysed with SPSS Statistics version 12.0.1. Descriptive analysis was used to analyse the demographic variables. The Spearman Correlation test was run to assess the association between the number of servings of fruit and vegetable with waist circumference. Meanwhile, the barriers of fruit and vegetable consumption were analysed in percentage. A significance level of $p<0.05$ was set for all statistical tests.

\subsection{Ethical approval}

This study was approved by the IIUM Research Ethics Committee (IREC) (ID No. IREC 2018-055).

\section{Results}

\subsection{Demographic characteristics of respondents}

A convenience sample of 290 female students was screened in the study. However, only 279 were eligible for recruitment as study participants. Eleven students were excluded due to meeting the exclusion criteria. The summary of demographic variables, including age, year of study, faculty, and waist circumference are tabulated in Table 1. The majority of the respondents were aged 22 years $(n=68,24.4 \%)$, year 1 students $(n=104,37.3 \%)$, Kulliyyah of Allied Health Sciences (KAHS) students $(\mathrm{n}=125,44.8 \%)$, and with less than $80 \mathrm{~cm}$ waist circumference ( $\mathrm{n}=198,71.0 \%)$.

Table 1. Demographic characteristics of respondents

\begin{tabular}{clc}
\hline Characteristics & & $\mathrm{n}(\%)$ \\
\hline \multirow{6}{*}{ Age } & 19 years old & $32(11.5 \%)$ \\
& 20 years old & $56(20.1 \%)$ \\
& 21 years old & $29(10.4 \%)$ \\
& 22 years old & $68(24.4 \%)$ \\
& 23 years old & $65(23.3 \%)$ \\
& 24 years old & $27(9.7 \%)$ \\
& 25 years old & $2(0.7 \%)$ \\
\hline \multirow{6}{*}{ Year of study } & Year 1 & $104(37.3 \%)$ \\
& Year 2 & $67(24.0 \%)$ \\
& Year 3 & $78(28.0 \%)$ \\
& Year 4 & $30(10.8 \%)$ \\
\hline \multirow{6}{*}{ Kulliyyah } & Allied Health Sciences & $125(44.8 \%)$ \\
& Science & $69(24.7 \%)$ \\
& Pharmacy & $53(19.0 \%)$ \\
& Nursing & $32(11.5 \%)$ \\
\hline \multirow{2}{*}{ Waist circumference } & $>80 \mathrm{~cm}$ & $81(29.0 \%)$ \\
& $<80 \mathrm{~cm}$ & $198(71.0 \%)$ \\
\hline
\end{tabular}

\subsection{Fruit and vegetable consumption}

Table 2 shows a summary of fruit consumption among female students. Notably, more than half of the students had only one serving of fruits a day $(n=151$, $54.1 \%)$, followed by no serving $(n=94,33.7 \%)$, two servings $(n=25,9.0 \%)$, and three servings $(n=9,3.2 \%)$. While for the frequency of intake, the majority of the students consumed fruits about one to three times a week $(n=115,41.2 \%)$ and less than once a week $(n=103$, $36.9 \%)$. Next, out of 279 students, 139 preferred to eat fruits during lunch $(33.3 \%)$, and 92 ate fruits during dinner $(22.1 \%)$. Out of a list of 11 fruits, the top three fruits favoured by the female students were apples $(\mathrm{n}=$ $129,29.0 \%)$, bananas $(\mathrm{n}=74,16.7 \%)$, and watermelons $(\mathrm{n}=50,11.3 \%)$, while the least favourite was pineapple 
Table 2. Fruits consumption among female university students

\begin{tabular}{|c|c|c|}
\hline Characteristics & & $\mathrm{n}(\%)$ \\
\hline \multirow{4}{*}{ Number of servings } & None & $94(33.7 \%)$ \\
\hline & 1 serving & $151(54.1 \%)$ \\
\hline & 2 servings & $25(9.0 \%)$ \\
\hline & 3 servings & $9(3.2 \%)$ \\
\hline \multirow{5}{*}{ Frequency of intake } & $\geq 1$ time/day & $25(9.0 \%)$ \\
\hline & $1-3$ times/week & $115(41.2 \%)$ \\
\hline & $4-6$ times/week & $26(9.3 \%)$ \\
\hline & $<1$ time/week & $103(36.9 \%)$ \\
\hline & Never & $10(3.6 \%)$ \\
\hline \multirow{6}{*}{ Timing of intake } & Breakfast & $51(12.2 \%)$ \\
\hline & Morning tea & $28(6.7 \%)$ \\
\hline & Lunch & $139(33.3 \%)$ \\
\hline & Afternoon tea & $65(15.6 \%)$ \\
\hline & Dinner & $92(22.1 \%)$ \\
\hline & Supper & $42(10.1 \%)$ \\
\hline \multirow{11}{*}{ Types of fruits } & Apple & $129(29.0 \%)$ \\
\hline & Banana & $74(16.7 \%)$ \\
\hline & Watermelon & $50(11.3 \%)$ \\
\hline & Guava & $48(10.8 \%)$ \\
\hline & Orange & $47(10.6 \%)$ \\
\hline & Papaya & $33(7.4 \%)$ \\
\hline & Honeydew & $25(5.6 \%)$ \\
\hline & Mango & $12(2.7 \%)$ \\
\hline & Pear & $12(2.7 \%)$ \\
\hline & Grapes & $11(2.5 \%)$ \\
\hline & Pineapple & $3(0.7 \%)$ \\
\hline
\end{tabular}

$(n=3,0.7 \%)$.

The consumption of vegetables among female students in IIUM is shown in Table 3 . Half of the students $(n=143,51.3 \%)$ took one serving of vegetables per day, while 87 of the respondents consumed two servings daily $(31.2 \%), 31$ respondents consumed no serving of vegetables $(11.1 \%)$, and 18 students had three servings daily $(6.5 \%)$. The frequency of vegetable intake was outstanding with once or more per day $(n=95$, $34.1 \%)$ and four to six times per week $(n=82,29.4 \%)$. Next, most of the students had vegetables in their meals during lunch $(\mathrm{n}=263,58.8 \%)$, followed by dinner $(\mathrm{n}=154,34.5 \%)$. Additionally, the top three vegetables preferred by the students were cabbage $(n=111,26.0 \%)$, kangkung $(\mathrm{n}=56,13.1 \%)$, and salad $(\mathrm{n}=55,12.9 \%)$, while the least preferred vegetable was tomato $(n=12$, $2.8 \%)$

\subsection{Association of fruit and vegetable intake with waist circumference}

Spearman's correlation test was run to analyse, which is tabulated in Table 4 . The results show no significant correlation between fruits intake, vegetable intake and waist circumference $(p=0.873 ; p=0.889)$ respectively.
Table 3. Vegetable consumption among female university students

\begin{tabular}{|c|c|c|}
\hline Characteristics & & $\mathrm{n}(\%)$ \\
\hline \multirow{4}{*}{ Number of servings } & None & $31(11.1 \%)$ \\
\hline & 1 serving & $143(51.3 \%)$ \\
\hline & 2 servings & $87(31.2 \%)$ \\
\hline & 3 servings & $18(6.5 \%)$ \\
\hline \multirow{5}{*}{ Frequency of intake } & $\geq 1$ time/day & $95(34.1 \%)$ \\
\hline & $1-3$ times/week & $69(24.7 \%)$ \\
\hline & $4-6$ times/week & $82(29.4 \%)$ \\
\hline & $<1$ time/week & $27(9.7 \%)$ \\
\hline & Never & $6(2.2 \%)$ \\
\hline \multirow{6}{*}{ Timing of intake } & Breakfast & $18(4.0 \%)$ \\
\hline & Morning tea & $1(0.2 \%)$ \\
\hline & Lunch & $263(58.8 \%)$ \\
\hline & Afternoon tea & $8(1.8 \%)$ \\
\hline & Dinner & $154(34.5 \%)$ \\
\hline & Supper & $3(0.7 \%)$ \\
\hline \multirow{11}{*}{ Types of vegetables } & Cabbage & $111(26.0 \%)$ \\
\hline & Kangkung & $56(13.1 \%)$ \\
\hline & Salad & $55(12.9 \%)$ \\
\hline & Mustard leave (sawi) & $46(10.7 \%)$ \\
\hline & Spinach & $33(7.7 \%)$ \\
\hline & Cucumber & $30(7.0 \%)$ \\
\hline & Leafy green & $27(6.3 \%)$ \\
\hline & Carrot & $25(5.8 \%)$ \\
\hline & Ulam-ulaman & $19(4.4 \%)$ \\
\hline & Long bean & $14(3.3 \%)$ \\
\hline & Tomato & $12(2.8 \%)$ \\
\hline
\end{tabular}

Table 4. Association of fruit and vegetable intake with waist circumference

\begin{tabular}{lcccc}
\hline & \multicolumn{2}{c}{$\mathrm{r}$} & \multicolumn{2}{c}{$\mathrm{p}$-value } \\
\cline { 2 - 5 } & Fruits & Vegetables & Fruits & Vegetables \\
\hline $\begin{array}{l}\text { Waist } \\
\begin{array}{l}\text { circumference }(\mathrm{cm}) \\
(\mathrm{n}=279)\end{array}\end{array}$ & -0.01 & -0.008 & 0.873 & 0.889 \\
\hline
\end{tabular}

\subsection{Barriers of fruit and vegetable consumption}

Based on Table 5, more than half of the students $(n=165,59.1 \%)$ reported that non-availability was the greatest barrier to them to consume fruits. The second barrier was the price of fruits $(n=65,23.3 \%)$, which was rather expensive for students. This explained the reason for the low intake of fruits among female students which was mostly only one serving per day and one to three times per week. For the option of 'others', students listed their barrier such as difficult to store fruits, forgot to eat, too lazy to buy and peel them off, financial limitation as a university student and need to buy fresh fruits outside the university.

Meanwhile, for vegetables, the trend of barriers was quite similar to that of fruits. The utmost barrier was not delicious ( $\mathrm{n}=69,24.7 \%)$ followed by difficult to eat three servings a day $(\mathrm{n}=62,22.2 \%)$, poor quality of vegetables $(\mathrm{n}=41,14.7 \%)$ and non-availability $(\mathrm{n}=40,14.3 \%)$. 
Table 5. Barriers of fruit and vegetable consumption among female university students

\begin{tabular}{clc}
\hline Characteristics & & $\mathrm{n}(\%)$ \\
\hline \multirow{5}{*}{ Fruits } & Difficult to eat 2 servings a day & $9(3.2 \%)$ \\
& Expensive & $65(23.3 \%)$ \\
& Not delicious & $6(2.2 \%)$ \\
& Non-availability & $165(59.1 \%)$ \\
& Fear of pesticides and other chemicals on fruit & $5(1.8 \%)$ \\
& Poor quality & $6(2.2 \%)$ \\
& Time constraint & $16(5.7 \%)$ \\
& Others & $7(2.5 \%)$ \\
\hline & Difficult to eat 3 servings a day & $62(22.2 \%)$ \\
& Expensive & $19(6.8 \%)$ \\
& Not delicious & $69(24.7 \%)$ \\
& Non-availability & $40(14.3 \%)$ \\
& Fear of pesticides and other chemicals on fruit & $23(8.2 \%)$ \\
& Poor quality & $41(14.7 \%)$ \\
& Time constraint & $8(2.9 \%)$ \\
& Others & $17(6.1 \%)$ \\
\hline
\end{tabular}

While for the 'others' option, some students indicated that there was no specific barrier to them consuming vegetables, worried about the cleanliness of vegetables prepared at the cafeteria, bad opinion and experience on vegetables since childhood, no appropriate storage at the hostel, choosy, limited choices at the cafeteria, and too little vegetables in a la carte meals at the cafeteria.

\section{Discussion}

This study identified fruit and vegetable intake among female university students, the association of fruit and vegetable intake with waist circumference and the barriers of intake.

\subsection{Fruit and vegetable consumption}

The findings of this study showed that most of the female students only had one serving of FV per day. Previous studies also reported similar findings on FV intakes such as one to two servings of fruits and only one serving of vegetables daily (Pessoa et al., 2015). A similar pattern was observed in the low-income urban African American youth where findings showed that only 1.5 servings of fruit and 1.8 servings of vegetables were consumed in a day (Trude et al., 2016).

On the other hand, the present study demonstrated that only $9.0 \%$ of students had fruits intake of two servings in a day; while $6.5 \%$ had vegetable intake of three servings per day to meet the intake recommended by the Malaysian Dietary Guideline (2010). The results were much lower than the result of Al-Otaibi (2014) where $22 \%$ of female students in a Saudi Arabia University consumed five or more servings of FV. Our findings were consistent with other studies which identified that young people and university students tend to consume below the recommended FV intake (Herbert et al., 2010; Gan et al., 2011; van den Bogerd et al., 2018). Moreover, studies among university students showed that only $20 \%$ of Pakistani students, $2.78 \%$ female Saudi Arabian students, and 7.3\% female German students consumed FV as per the recommended daily intake (Al-Otaibi, 2014; Alsunni and Badar, 2015; Teschl et al., 2018). Teschl et al. (2018) and van den Bogerd et al. (2018) noted that students who met the recommended FV intake had general knowledge about the recommended intake and were living in shared households as the cost for $\mathrm{FV}$ groceries was more affordable. Similarly, as reported by Lutfiyya et al. (2012), most Americans failed to consume FV to meet the recommended servings, with rural residents being at greater risk for not making healthy dietary choices. This could be due to environmental access issues and affordability.

For frequency of intake, fruits were consumed one to three times a week and less than once a week, while for vegetable intake was once or more per day and four to six times per week. This was in line with the findings by Kpodo et al. (2015) which stated that $36.6 \%$ of Ghanaian students had fruits intake between one to five times a week. Pessoa and colleagues (2015) also identified five or more days of FV intake a week. However, this is contradictory with Kpodo et al. (2015) where more than half of the sampled Ghanaian students had vegetables at least three times per day. In addition, if FV intake was compared to the frequency of once or more per day, students had more vegetables compared to fruits daily. This finding was supported by evidence from studies in Tanzania and Sri Lanka (Perera and Madhujith, 2012; Msambichaka et al., 2018). 
Regarding the timing of the FV intake, the present study showed that the majority of female students consumed FV during lunch and dinner. This was aligned with Perera and Madhujith (2012) where female students liked to eat fruits during the main meals and had vegetables during lunch and dinner. A similar observation was presented in a study by Pedersen et al. (2012) where vegetable consumption was strongly associated with lunch consumption. Nago et al. (2012) reported that fruits were preferably consumed at night or as desserts, and the authors mentioned that some of the commonly consumed vegetables such as onions and tomato were used in most of the cooking preparation of everyday meals. Sugiyama et al. (2012) stated that the FV intake during breakfast was less likely due to other choices of breakfast such as bread and other cooked foods which could also differ according to the breakfast style of individuals.

\subsection{Association of fruit and vegetable intake with waist circumference}

The present study found no significant correlation between fruits as well as vegetable intake with waist circumference. The findings were consistent with a study conducted among female Iranian university students which concluded that no significant association between FV intake with waist circumference (Ghalaeh et al., 2012). The results are also parallel with findings by Reis et al. (2014) and Schwingshackl et al. (2015). On another perspective from Ledoux et al. (2011) in their review article, they found that there was a weak association between FV consumption and adiposity. Moreover, the association was not mutually exclusive and could be due to multiple weight-related behaviours; and one of them was reduced intake of energy-dense foods in compensation of increased FV intake.

\subsection{Barriers of fruit and vegetable consumption}

The most-reported barriers of fruits intake among students were 'non-availability' and 'expensive'. While the barriers in vegetable consumption were 'not delicious', 'difficult to eat three servings a day', 'poor quality' and 'non-availability'.

Studies also reported that availability and prices were significant barriers to intake (Herbet et al., 2010; Othman et al., 2012; Perera and Madhujith, 2012; AlOtaibi, 2015). The findings align with Nago et al. (2012) whereby limited availability and accessibility in terms of the form, place and time were barriers to FV consumption. Thornton et al. (2012) noted that easy access to supermarkets was also related to increased FV consumption. With the consideration that university students did not have a fixed income, purchasing FV as part of their groceries might be slightly unfeasible. Dunn et al. (2011) revealed that purchasing of FV increased when the income of the households increased too. This indicates that people will buy more fruits if they have a higher income or if the prices are lower and affordable, as well as easily accessible.

The financial support for students is either from parents or other sources, and it plays a significant role in determining the intake of FV (Perera and Madhujith, 2012). Al-Otaibi (2015) also found that young females believed that the price of FV was high. Furthermore, the intake of FV was associated with wealth as rich people afford to buy FV compared to those with low incomes (Yen and Tan, 2012). Similarly, Malaysian adults with higher incomes demonstrated greater consumption of vegetables than those from lower-income groups as they believed that people with lower incomes tended to spend most of the income on their basic needs instead (Othman et al., 2012). A study in Port Vila, Vanuatu disclosed that about $20 \%$ of the total budget and more than $40 \%$ of the food budget of the poorest households were required in order to purchase the recommended amount of $\mathrm{FV}$ for all household members (Jones and Charlton, 2015). The difference in financial stability proved that it might also affect the affordability and thus the consumption of FV (Miller et al., 2016). Other than financially compromise as a barrier to FV intake, it was also related to education level and age, and frequency and access to unhealthy food especially in socio-economically underprivileged communities (Pessoa et al., 2015; Okop et al., 2019).

As for the barrier to vegetable consumption, 'not delicious' was a factor consistent with Herbet et al. (2010) and Lucan et al. (2010) where sensory factors such as taste or flavour played an important role in consumption. In a review article by Krølner et al. (2011), the authors argued that vegetables were often linked to unappealing and negative tastes such as bitter and insipid, and sometimes these taste perceptions were more likely based on prejudice than the actual taste. Nevertheless, the same article highlighted that the taste of fruits was generally preferred compared to the taste of vegetables. This was supported by Nago et al. (2012), who identified that most of the participants in their study preferred sweet-tasting fruits compared to bitter vegetables. It was further explained that this personal taste might also be affected by the way the vegetables were prepared (Nago et al., 2012). Besides, FV intakes were considered an inconvenient snack food due to the meticulous preparations needed before FV was ready to be served (Krølner et al., 2011). In short, consumption was in accordance with one's preference and acceptance of certain foods. 
The limitations of this present study include the probability of self-reported bias and incomplete answers as the questionnaire was self-administered. In addition, other data on anthropometry assessment and modifying factors were not assessed. Despite that, the use of strict inclusion and exclusion criteria to identify eligible respondents was recognised as important strengths of this study.

For future study, the food recording method is suggested for a more detailed data collection on dietary intake as well as the inclusion of other anthropometry assessment. Moreover, further research on other modifying factors such as physical activity and knowledge on FV intake can be examined. The target population can be expanded with the inclusion of male students for gender comparison in FV intake, differences in preference of $\mathrm{FV}$ and the barriers of $\mathrm{FV}$ consumption. Intervention can then be planned accordingly for this population. A study showed that participation in FV intervention study has demonstrated an outstanding and positive outcome such as increased FV liking and intake, as well as diminishing the barriers to FV consumption (Neville et al., 2015).

\section{Conclusion}

In conclusion, most of the female university students did not meet the recommended daily intake of FV based on serving size with the varied frequency of intake. The participants displayed preferences towards several types of FV, and the most common barriers to FV consumption were identified. Thus, the strategy of promoting a healthy lifestyle, specifically on increasing FV consumption, as well as overcoming the barriers among university students can be planned for successful implementation.

\section{Conflict of interest}

All authors declare no conflict of interest pertaining to this study.

\section{Acknowledgement}

We would like to thank the study respondents for their participation. This study was funded by the Research Initiative Grant Scheme, International Islamic University Malaysia (RIGS17-034-0609).

\section{References}

Al-Otaibi, H.H. (2014). The Pattern of Fruit and Vegetable Consumption among Saudi University Students. Global Journal of Health Science, 6(2), 155-162. https://doi.org/10.5539/gihs.v6n2p155
Al-Otaibi, H.H. (2015). Factors influencing Fruit and Vegetable Intake in Adolescents. In Ostojic, S.M. (Ed). Human Health and Nutrition. p. 184-200. Hauppauge, New York, USA: Nova Science Publishers, Inc.

Alsunni, A.A. and Badar, A. (2015). Fruit and vegetable consumption and its determinants among Saudi university students. Journal of Taibah University Medical Sciences, 10(2), 201-207. https:// doi.org/10.1016/j.jtumed.2014.11.003

Aune, D., Giovannucci, E., Boffetta, P., Fadnes, L.T., Keum, N., Norat, T., Greenwood, D.C., Riboli, E., Vatten, L.J. and Tonstad, S. (2017). Fruit and vegetable intake and the risk of cardiovascular disease, total cancer and all-cause mortality-a systematic review and dose-response meta-analysis of prospective studies. International Journal of Epidemiology, 46(3), 1029-1056. https:// doi.org/10.1093/ije/dyw319

Bishwajit, G., O'Leary, D.P., Ghosh, S., Sanni, Y., Shangfeng, T. and Zhanchun, F. (2017). Association between depression and fruit and vegetable consumption among adults in South Asia. BMC Psychiatry, 17, 15. https://doi.org/10.1186/s12888017-1198-1

Cooper, A.J., Forouhi, N.G., Ye, Z., Buijsse, B., Arriola, L., Balkau, B., Barricarte, A., Beulens, J.W., Boeing, H., Büchner, F.L., Dahm, C.C., de Lauzon-Guillain, B., Fagherazzi, G., Franks, P.W., Gonzalez, C., Grioni, S., Kaaks, R., Key, T.J., Masala, G., Navarro, C., Nilsson, P., Overvad, K., Panico, S., Ramón Quirós, J., Rolandsson, O., Roswall, N., Sacerdote, C., Sánchez, M.J., Slimani, N., Sluijs, I., Spijkerman, A.M., Teucher, B., Tjonneland, A., Tumino, R., Sharp, S.J., Langenberg, C., Feskens, E.J., Riboli, E. and Wareham, N.J. (2012). Fruit and vegetable intake and type 2 diabetes: EPIC-InterAct prospective study and meta-analysis. European Journal of Clinical Nutrition, 66(10), 1082-1092. https://doi.org/10.1038/ejen.2012.85

Dunn, R.A., Sharkey, J.R., Lotade-Manje, J., Bouhlal, Y. and Nayga Jr, R.M. (2011). Socio-economic status, racial composition and the affordability of fresh fruits and vegetables in neighborhoods of a large rural region in Texas. Nutrition Journal, 10, 6. https://doi.org/10.1186/1475-2891-10-6

Gan, W.Y., Mohd Nasir, M.T., Zalilah, M.S. and Hazizi, A.S. (2011). Differences in eating behaviours, dietary intake and body weight status between male and female Malaysian University students. Malaysian Journal of Nutrition, 17(2), 213228. 
Ghalaeh, R.S., Gholi, Z., Bank, S.S. and Azadbakht, L. (2012). Fruit and vegetable intake, body mass index and waist circumference among young female students in Isfahan. Journal of Education and Health Promotion, 1, 29. https://doi.org/10.4103/22779531.99969

Government of Ireland. (2016). Healthy Eating Guidelines. Retrieved on October 4, 2017, from Healthy Ireland Website: www.healthyireland.ie/ health-initiatives/heg/

Hakim, N.A., Muniandy, N. and Danish, A. (2012). Nutritional Status and Eating Practices among University Students in Selected Universities in Selangor, Malaysia. Asian Journal of Clinical Nutrition, 4(3), 77-87. https:// doi.org/10.3923/ajen.2012.77.87

Hall, J.N., Moore, S., Harper, S.B. and Lynch, J.W. (2009). Global Variability in Fruit and Vegetable Consumption. American Journal of Preventive Medicine, 36(5), 402-409. https://doi.org/10.1016/ j.amepre.2009.01.029

Hartley, L., Igbinedion, E., Holmes, J., Flowers, N., Thorogood, M., Clarke, A., Stranges, S., Hooper, L. and Rees, K. (2013). Increased consumption of fruit and vegetables for the primary prevention of cardiovascular diseases. Cochrane Database of Systematic Reviews, 6, CD009874. https:// doi.org/10.1002/14651858.CD009874.pub2

Herbert, G., Butler, L., Kennedy, O. and Lobb, A. (2010). Young UK adults and the 5 A DAY campaign: perceived benefits and barriers of eating more fruits and vegetables. International Journal of Consumer Studies, 34(6), 657-664. https:// doi.org/10.1111/j.1470-6431.2010.00872.x

Institute for Public Health (2014). National Health and Morbidity Survey 2014: Malaysian Adult Nutrition Survey. Vol 1: Methodology and General Findings. Kuala Lumpur, Malaysia: Ministry of Health Malaysia,

Institute for Public Health (2015). National Health and Morbidity Survey 2015 (NHMS 2015). Vol. II: NonCommunicable Diseases, Risk Factors and Other Health Problems. Kuala Lumpur, Malaysia: Ministry of Health Malaysia,

Jones, H.A. and Charlton, K.E. (2015). A cross-sectional analysis of the cost and affordability of achieving recommended intakes of non-starchy fruits and vegetables in the capital of Vanuatu. BMC Public Health, 15, 301. https://doi.org/10.1186/s12889-0151644-2

Kpodo, F.M., Mensah, C. and Dzah, C.S. (2015). Fruit and Vegetable Consumption Patterns and
Preferences of Students in a Ghanaian Polytechnic. World Journal of Nutrition and Health, 3(3), 53-59.

Krølner, R., Rasmussen, M., Brug, J., Klepp, K., Wind, M. and Due, P. (2011). Determinants of fruit and vegetable consumption among children and adolescents: a review of the literature. Part II: qualitative studies. International Journal of Behavioral Nutrition and Physical Activity, 8, 112. https://doi.org/10.1186/1479-5868-8-112

Ledoux, T.A., Hingle, M.D. and Baranowski, T. (2010). Relationship of fruit and vegetable intake with adiposity: a systematic review. Obesity Reviews, 12 (5), e143-e150. https://doi.org/10.1111/j.1467789X.2010.00786.X

Li, M., Fan, Y., Zhang, X., Hou, W. and Tang, Z. (2014). Fruit and vegetable intake and risk of type 2 diabetes mellitus: meta-analysis of prospective cohort studies. BMJ Open, 4(11), e005497. https://doi.org/10.1136/ bmjopen-2014-005497

Lucan, S.C., Barg, F.K. and Long, J.A. (2010). Promoters and Barriers to Fruit, Vegetable, and FastFood Consumption Among Urban, Low-Income African Americans-A Qualitative Approach. American Journal of Public Health, 100 (4), 631-635. https://doi.org/10.2105/ AJPH.2009.172692

Lutfiyya, M.N., Chang, L.F. and Lipsky, M.S. (2012). A cross-sectional study of US rural adults' consumption of fruits and vegetables: do they consume at least five servings daily? BMC Public Health, 12, 280. https://doi.org/10.1186/1471-2458$12-280$

Micha, R., Khatibzadeh, S., Shi, P., Andrews, K.G., Engell, R.E. and Mozaffarian, D. (2015). Global, regional and national consumption of major food groups in 1990 and 2010: a systematic analysis including 266 country-specific nutrition surveys worldwide. BMJ Open, 5(9), e008705. https:// doi.org/10.1136/bmjopen-2015-008705

Miller, V., Yusuf, S., Chow, C.K., Dehghan, M., Corsi, D.J., Lock, K., Popkin, B., Rangarajan, S., Khatib, R., Lear, S.A., Mony, P., Kaur, M., Mohan, V., Vijayakumar, K., Gupta, R., Kruger, A., Tsolekile, L., Mohammadifard, N., Rahman, O., Rosengren, A., Avezum, A., Orlandini, A., Ismail, N., Lopez-Jaramillo, P., Yusufali, A., Karsidag, K., Iqbal, R., Chifamba, J., Oakley, S.M., Ariffin, F., Zatonska, K., Poirier, P., Wei, L., Jian, B., Hui, C., Xu, L., Xiulin, B., Teo, K. and Mente, A. (2016). Availability, affordability, and consumption of fruits and vegetables in 18 countries across income levels: findings from the Prospective 
Urban Rural Epidemiology (PURE) study. The Lancet Global Health, 4(10), e695-e703. https:// doi.org/10.1016/S2214-109X(16)30186-3

Mo, X., Gai, R.T., Sawada, K., Takahashi, Y., Cox, S.E., Nakayama, T. and Mori, R. (2019). Coronary heart disease and stroke disease burden attributable to fruit and vegetable intake in Japan: projected DALYS to 2060. BMC Public Health, 19, 707. https:// doi.org/10.1186/s12889-019-7047-z

Msambichaka, B., Eze, I.C., Abdul, R., Abdulla, S., Klatser, P., Tanner, M., Kaushik, R., Geubbels, E. and Probst-Hensch, N. (2018). Insufficient Fruit and Vegetable Intake in a Low- and Middle-Income Setting: A Population-Based Survey in Semi-Urban Tanzania. Nutrients, 10(2), 222. https:// doi.org/10.3390/nu10020222

Mytton, O.T., Nnoaham, K., Eyles, H., Scarborough, P. and Mhurchu, C.N. (2014). Systematic review and meta-analysis of the effect of increased vegetable and fruit consumption on body weight and energy intake. BMC Public Health, 14(886), 2-11. https:// doi.org/10.1186/1471-2458-14-886

Nago, E.S., Verstraeten, R., Lachat, C.K., Dossa, R.A. and Kolsteren, P.W. (2012). Food Safety Is a Key Determinant of Fruit and Vegetable Consumption in Urban Beninese Adolescents. Journal of Nutrition Education and Behavior, 44(6), 548-555. https:// doi.org/10.1016/j.jneb.2011.06.006

National Coordinating Committee on Food and Nutrition (2010). Malaysian Dietary Guidelines. Putrajaya, Malaysia: Ministry of Health Malaysia.

Neville, C.E., McKinley, M.C., Draffin, C.R., Gallagher, N.E., Appleton, K.M., Young, I.S., Edgar, J.D. and Woodside, J.V. (2015). Participating in a fruit and vegetable intervention trial improves longer term fruit and vegetable consumption and barriers to fruit and vegetable consumption: a follow-up of the ADIT study. International Journal of Behavioral Nutrition and Physical Activity, 12(1), $158 . \quad$ https:// doi.org/10.1186/s12966-015-0311-4

Okop, K.J., Ndayi, K., Tsolekile, L., Sanders, D. and Puoane, T. (2019). Low intake of commonly available fruits and vegetables in socio-economically disadvantaged communities of South Africa: influence of affordability and sugary drinks intake. BMC Public Health, 19, 940. https:// doi.org/10.1186/s12889-019-7254-7

Othman, K.I., Ab Karim, M.S., Karim, R., Adzhan, N., Halim, N.A. and Osman, S. (2012). Factors influencing fruits and vegetables consumption behaviour among adults in Malaysia. Journal of Agribusiness Marketing, 5, 29-46.
Pedersen, T.P., Meilstrup, C., Holstein, B.E. and Rasmussen, M. (2012). Fruit and vegetable intake is associated with frequency of breakfast, lunch and evening meal: cross-sectional study of 11-, 13-, and 15-year-olds. International Journal of Behavioral Nutrition and Physical Activity, 9, 9. https:// doi.org/10.1186/1479-5868-9-9

Pem, D. and Jeewon, R. (2015). Fruit and Vegetable Intake: Benefits and Progress of Nutrition Education Interventions-Narrative Review Article. Iranian Journal of Public Health, 44(10), 1309-1321.

Perera, T. and Madhujith, T. (2012). The Pattern of Consumption of Fruits and Vegetables by Undergraduate Students: A Case Study. Tropical Agricultural Research, 23(3), 261-271. https:// doi.org/10.4038/tar.v23i3.4663

Pessoa, M.C., Mendes, L.L., Gomes, C.S., Martins, P.A. and Velasquez-Melendez, G. (2015). Food environment and fruit and vegetable intake in a urban population: A multilevel analysis. BMC Public Health, 15, 1012. https://doi.org/10.1186/s12889015-2277-1

Reis, L.C., Correia, I.C. and Mizutani, E.S. (2014). Stages of changes for fruit and vegetable intake and their relation to the nutritional status of undergraduate students. Einstein (São Paulo), 12(1), 48-54. 45082014AO2926

Richard, A., Rohrmann, S., Vandeleur, C.L., MohlerKuo, M. and Eichholzer, M. (2015). Associations between fruit and vegetable consumption and psychological distress: results from a populationbased study. BMC Psychiatry, 15, 213. https:// doi.org/10.1186/s12888-015-0597-4

Schwingshackl, L., Hoffmann, G., Kalle-Uhlmann, T., Arregui, M., Buijsse, B. and Boeing, H. (2015). Fruit and Vegetable Consumption and Changes in Anthropometric Variables in Adult Populations: A Systematic Review and Meta-Analysis of Prospective Cohort Studies. PLoS ONE, 10(10), e0140846. https://doi.org/10.1371/ journal.pone. 0140846

Slavin, J.L. and Lloyd, B. (2012). Health Benefits of Fruits and Vegetables. Advances in Nutrition: An International Review Journal, 3(4), 506-516. https:// doi.org/10.3945/an.112.002154

Sugiyama, S., Okuda, M., Sasaki, S., Kunitsugu, I. and Hobara, T. (2012). Breakfast habits among adolescents and their association with daily energy and fish, vegetable, and fruit intake: a communitybased cross-sectional study. Environmental Health and Preventive Medicine, 17(5), 408-414. https:// 
doi.org/10.1007/s12199-012-0270-1

Ta, M.L., VanEenwyk, J. and Bensley, L. (2012). Limited Percentages of Adults in Washington State Meet the Dietary Guidelines for Americans Recommended Intakes of Fruits and Vegetables. Journal of the Academy of Nutrition and Dietetics, 112(5), 699-704. https://doi.org/10.1016/ j.jand.2011.12.005

Tee, E.S. (2011). Development and promotion of Malaysian Dietary Guidelines. Asia Pacific Journal of Clinical Nutrition, 20(3), 455-461.

Teschl, C., Nössler, C., Schneider, M., Carlsohn, A. and Lührmann, P. (2018). Vegetable consumption among university students: Relationship between vegetable intake, knowledge of recommended vegetable servings and self-assessed achievement of vegetable intake recommendations. Health Education Journal, 77(4), 398-411. https:// doi.org/10.1177/0017896917751833

Thornton, L.E., Pearce, J.R., Macdonald, L., Lamb, K.E. and Ellaway, A. (2012). Does the choice of neighbourhood supermarket access measure influence associations with individual-level fruit and vegetable consumption? A case study from Glasgow. International Journal of Health Geographics, 11, 29. https://doi.org/10.1186/1476-072X-11-29

Trude, A.C.B., Kharmats, A.Y., Hurley, K.M., Anderson Steeves, E., Talegawkar, S.A. and Gittelsohn, J. (2016). Household, psychosocial, and individuallevel factors associated with fruit, vegetable, and fiber intake among low-income urban African American youth. BMC Public Health, 16, 872. https://doi.org/10.1186/s12889-016-3499-6

Van den Bogerd, N., Maas, J., Seidell, J.C. and Dijkstra, S.C. (2018). Fruit and vegetable intakes, associated characteristics and perceptions of current and future availability in Dutch university students. Public Health Nutrition, 22(11), 1951-1959. https:// doi.org/10.1017/S136898001800174X

Wang, X., Ouyang, Y., Liu, J., Zhu, M., Zhao, G., Bao, W. and Hu, F.B. (2014). Fruit and vegetable consumption and mortality from all causes, cardiovascular disease, and cancer: systematic review and dose-response meta-analysis of prospective cohort studies. BMJ, 349, g4490. https:// doi.org/10.1136/bmj.g4490

World Health Organisation (WHO). (2003). Promoting fruit and vegetable consumption around the world. (2003). Retrieved on October 4, 2017, from WHO Website: www.who.int/dietphysicalactivity/fruit/en/

World Health Organisation (WHO). (2008). Waist Circumference and Waist-Hip Ratio: Report of a
WHO Expert Consultation. Geneva: WHO Document Production Services.

World Health Organization (WHO): e-Library of Evidence for Nutrition Actions (eLENA). (2019). Increasing fruit and vegetable consumption to reduce the risk of noncommunicable diseases. Retrieved on October 2, 2019 from FSIS Website: www.who.int/ elena/titles/fruit_vegetables_ncds/en/

Yen, S.T. and Tan, A.K. (2012). Who are eating and not eating fruits and vegetables in Malaysia? International Journal of Public Health, 57 (6), 945-951. https://doi.org/10.1007/s00038-0120343-3

Yip, C.S.C., Chan, W. and Fielding, R. (2019). The Associations of Fruit and Vegetable Intakes with Burden of Diseases: A Systematic Review of MetaAnalyses. Journal of the Academy of Nutrition and Dietetics, 119(3), 464-481. https://doi.org/10.1016/ j.jand.2018.11.007

Yu, Z.M., DeClercq, V., Cui, Y., Forbes, C., Grandy, S., Keats, M., Parker, L., Sweeney, E. and Dummer, T.J.B. (2018). Fruit and vegetable intake and body adiposity among populations in Eastern Canada: the Atlantic Partnership for Tomorrow's Health Study. BMJ Open, 8(4), e018060. https://doi.org/10.1136/ bmjopen-2017-018060

Zhang, C., Rexrode, K.M., Van Dam, R.M., Li, T.Y. and Hu, F.B. (2008). Abdominal obesity and the risk of all-cause, cardiovascular, and cancer mortality: Sixteen years of follow-up in US women. Circulation, 117(13), 1658-1667. https:// doi.org/10.1161/CIRCULATIONAHA.107.739714 